University of South Florida

DIGITAL COMMONS

Digital Commons @ University of

@ UNIVERSITY OF SOUTH FLORIDA

South Florida

KIP Articles

KIP Research Publications

January 2010

\title{
Urban geophysics: a mapping of Mount Bonnell fault and its \\ karstic features in Austin, TX
}

Mustafa Saribudak

Follow this and additional works at: https://digitalcommons.usf.edu/kip_articles

\section{Recommended Citation}

Saribudak, Mustafa, "Urban geophysics: a mapping of Mount Bonnell fault and its karstic features in Austin, TX" (2010). KIP Articles. 5816.

https://digitalcommons.usf.edu/kip_articles/5816

This Article is brought to you for free and open access by the KIP Research Publications at Digital Commons @ University of South Florida. It has been accepted for inclusion in KIP Articles by an authorized administrator of Digital Commons @ University of South Florida. For more information, please contact digitalcommons@usf.edu. 


\title{
URBAN GEOPHYSICS: A MAPPING OF MOUNT BONNELL FAULT AND ITS KARSTIC FEATURES IN AUSTIN, TX
}

\author{
Mustafa Saribudak, Environmental Geophysics Associates, Austin, TX
}

\begin{abstract}
Although most karstic regions are characterized by caves, collapsed features, and sinkholes, such features often do not have surface expressions, and their presence may go unrecorded. Central Texas and the Greater Austin metropolitan area have been built on the karstic limestone (Lower Cretaceous of Glen Rose Formation and Edwards Aquifer) in the Balcones Fault Zone (BFZ), and their growth is expanding. Near-surface karst features in the Austin area have a profound effect upon geotechnical engineering studies, such as structural foundations (residential buildings, shopping malls), utility excavations, tunnels, pavements and cut slopes. Thus the practice of geotechnical engineering is and has been a challenging proposition in the Austin area.

Geophysical methods are sporadically used to estimate the locations and parameters of these karst features prior to any of these above-mentioned geotechnical studies. Opinions concerning the effectiveness of these geophysical surveys are mixed, and geophysical techniques are not generally recognized as primary tools in engineering-scale studies.

However, remarkable advances in the manufacturing of geophysical instruments over the last ten years have made geophysics a viable tool for geotechnical studies of these karstic features. Data quality has been increased by the advent of continuous data collection. The data are better processed and interpreted by new and improved software packages, which produce improved sub-surface imaging and mapping.

Thus integrated geophysical surveys can provide new insight into the near-surface karstic features in the Glen Rose Formation and Edwards Aquifer. I have conducted geophysical surveys (ground penetrating radar [GPR], resistivity imaging, magnetic [G-858], conductivity [EM-31] and natural potential $[\mathrm{NP}]$ ) at three locations where the Mount Bonnell fault (MBF) is present, along the northern limiting boundary of the BFZ. Results indicate that all methods successfully imaged significant karst anomalies across the known fault locations. Integration of all these anomalies provides a much better understanding of near-surface geology defined by the caves, voids, collapsed materials, sinkholes and the fault itself.
\end{abstract}

\section{Introduction}

A study of the geologic map of Austin by Garner et., al., (1976) shows that normal faults along the BFZ are some of the main features, if not the primary features, that have shaped the geology and physiography of the city and its environs. At the regional scale, faults have positioned the geologic unit into a framework that juxtaposes contrasting rock, soil, and terrain, thereby establishing a major physiographic boundary: the Balcones Escarpment, which extends through west Austin, separates the Edwards Plateau to the west from the Blackland Prairies of the Gulf Coastal Plain to the east (Collins and Woodruff, 2001). The Balcones escarpment, with a topographic relief as great as 300 feet in Austin, is a fault-line scarp, and consists of normal faults, which dip toward the east and southeast. The BFZ's most prominent fault is the Mount Bonnell fault, which composes the northernmost part of the fault zone 
with a throw of near 600 feet. The Lower Cretaceous Glen Rose Formation is at the surface to the west of the MBF, while east of the fault zone younger rocks of Edwards Aquifer are at the surface (Figure 1).

Geophysical methods have been an important component of effective hydrogeological investigations over the Edwards Aquifer. Geophysical surveys employing variety of electrical and electromagnetic methods have been used to successfully map stratigraphy, geologic structure, and depth to the water table in major aquifer systems (e.g., Fitterman and Stewart, 1985; Connor and Sandberg, 2001).

In this study, however, I demonstrate the utility of integrated surveys for the near-surface characterization of the MBF in the Austin area (Figure 2). To my knowledge, this is the first application of integrated geophysical techniques to the characterization of faults, fractures, caves, sinkholes and collapsed features in the metropolitan Austin area. The geophysical surveys were performed at the intersections of: 1) Height Drive and Highway 360; 2) West Park Drive and Highway 360; and 3) Bee Cave Road and Camp Craft Road (Figure 2). Conductivity, magnetic, GPR and NP methods were chosen for their ability to very rapidly map variations of their respective physical attributes (e.g., conductivity, magnetic susceptibility, dielectric contrast and ambient electrical current in miliVolts) within the surface. 2D resistivity imaging surveys were conducted to provide information about variation in electrical resistivity as a function of depth. Results of these surveys are described in the following.

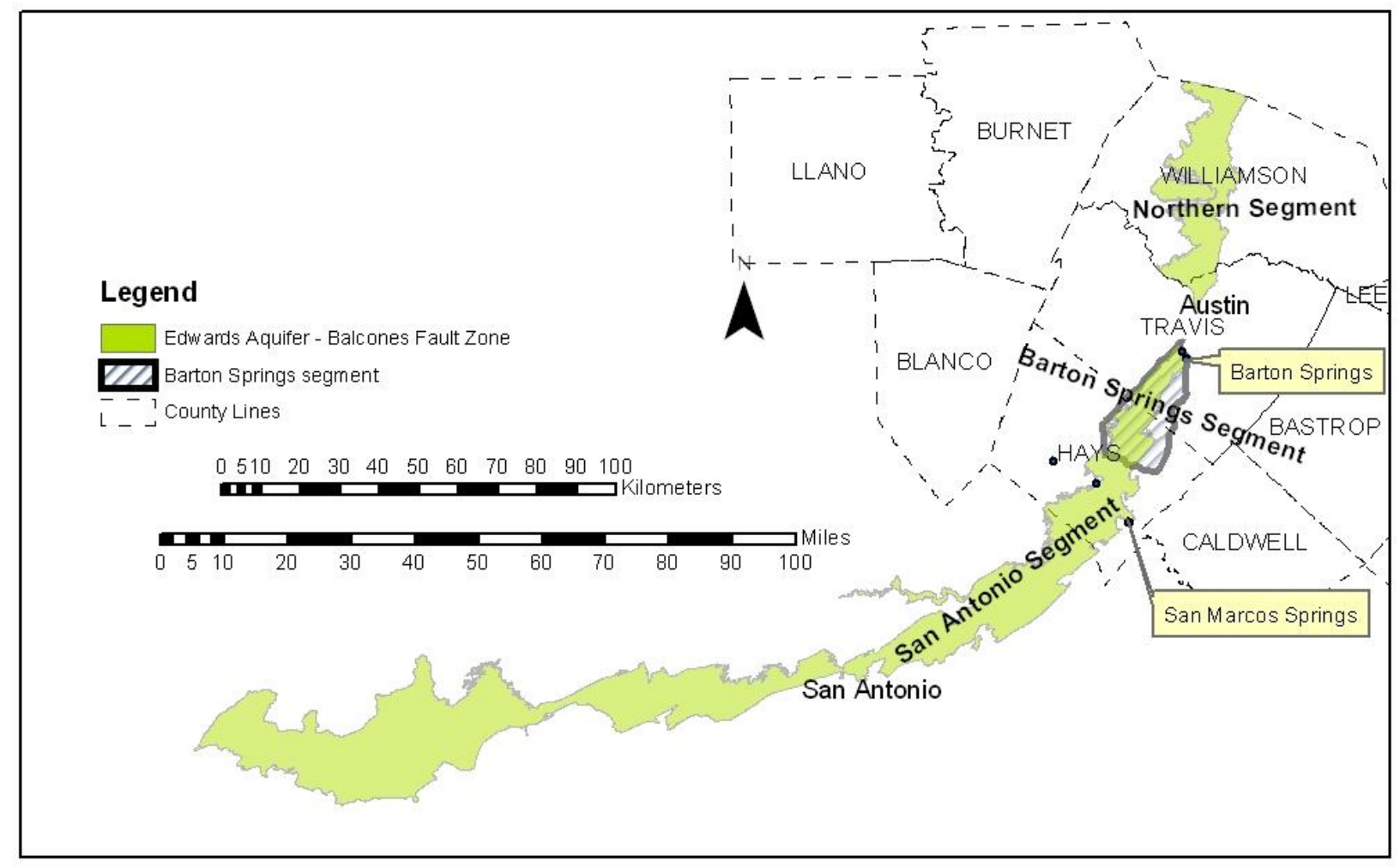

Figure 1: Balcones Fault Zone Portion of the Edwards Aquifer in Central Texas. 

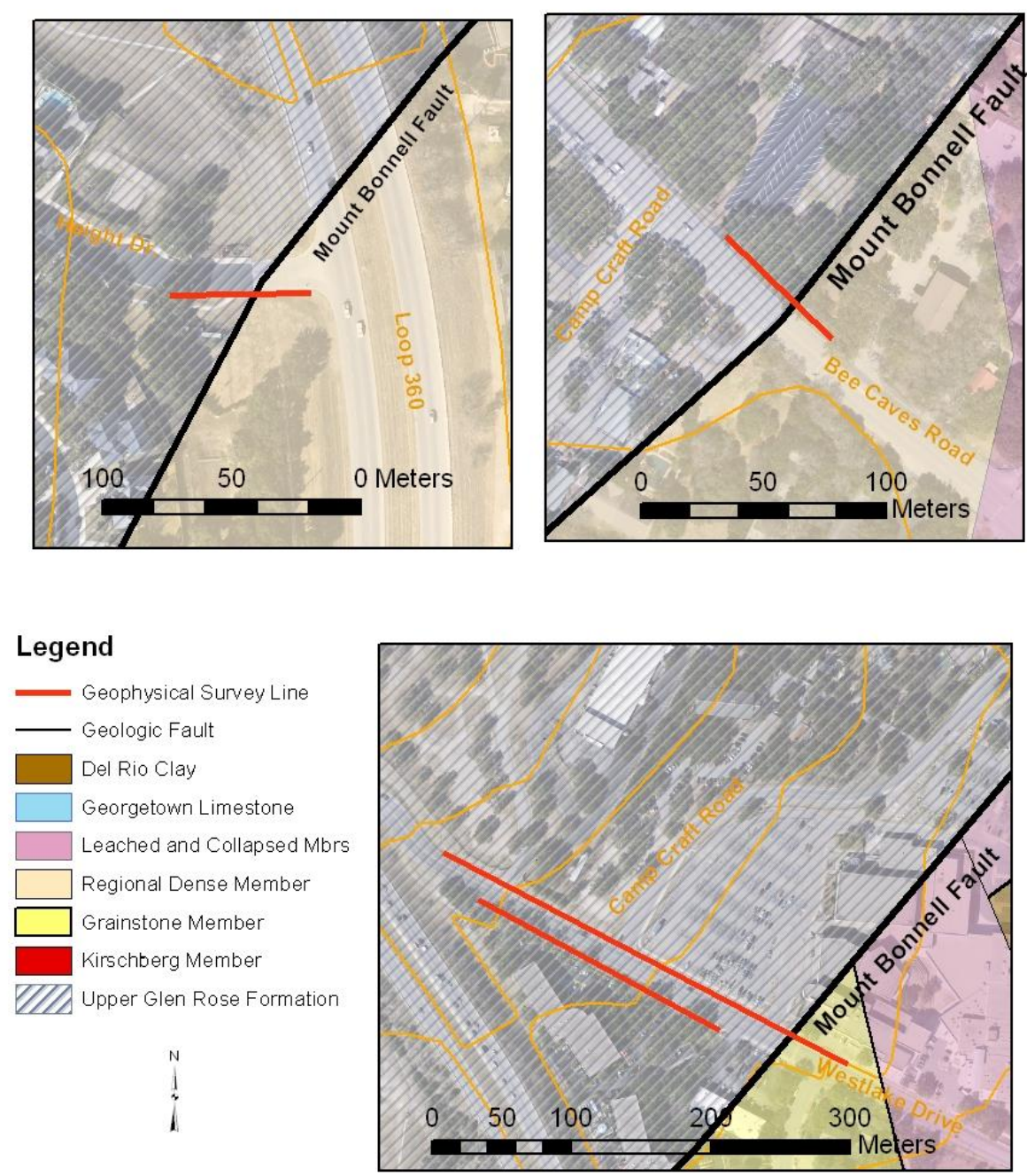

Figure 2: Surface geology of geophysical survey sites. Geologic interpretation modified from Hauwert, 2009 and Rodda et al. (1970) by Nico Hauwert.

\section{Geophysical Results}

\section{Height Drive Site at Highway 360}

A site map of the study area including the location of geophysical profiles and the MBF is shown in Figure 3. The magnetic and conductivity data are shown in Figure 4. Resistivity and NP data are shown in Figure 5. And 3-D GPR depth slices are given in Figure 6. The magnetic data indicate a high anomaly between the stations at 270 and 290 feet, whereas the conductivity data shows a high and low between the stations at 270 and 310 feet. These anomalies correspond to a very significant resistivity anomaly between stations 280 and 320 feet. The source of the anomaly appears to be the soil-filled material on top of a cave. The rest of the resistivity data between the stations at 320 and 418 feet shows significant resistivity anomalies: Low resistivity values shown in blue branch into higher resistivity values. This type of resistivity anomaly usually is an indicator of cave structures. The NP anomaly 
shown in Figure 5, along with the resistivity data show a very significant "sine-wave" shaped anomaly where the MBF is located. In addition, the rest of the NP anomaly shows cave-like anomalies. The 3D GPR depth slices in Figure 6 indicate the trend of the MBF and three underground pipes.

In summary, NP and the GPR data indicate the location of the MBF, which is consistent with the geological data (Hauwert, 2009). The resistivity, NP, magnetic and conductivity data show cave-like anomalies. GPR, magnetic and conductivity data show location of subsurface pipes across the study area. Findings of geophysical surveys are given in Table 1. There is a patched asphalt area on Height Drive where the fault crosses, and the repair on the site may have been necessary because of the nearsurface deformation due to the karstic features.

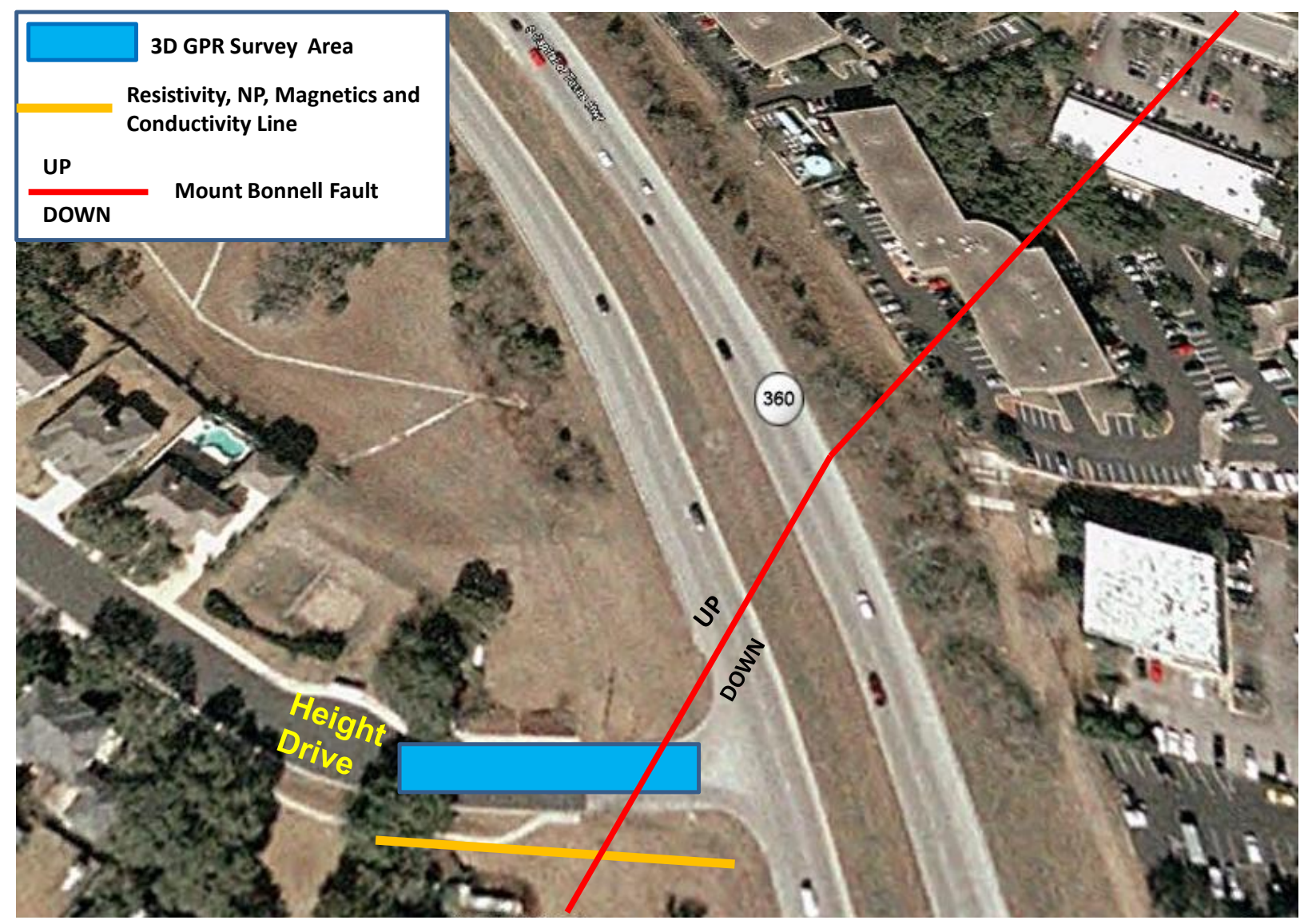

Figure 3: Site map showing the location of geophysical profiles and the Mount Bonnell fault. The fault location is taken from Hauwert, N., 2009. 


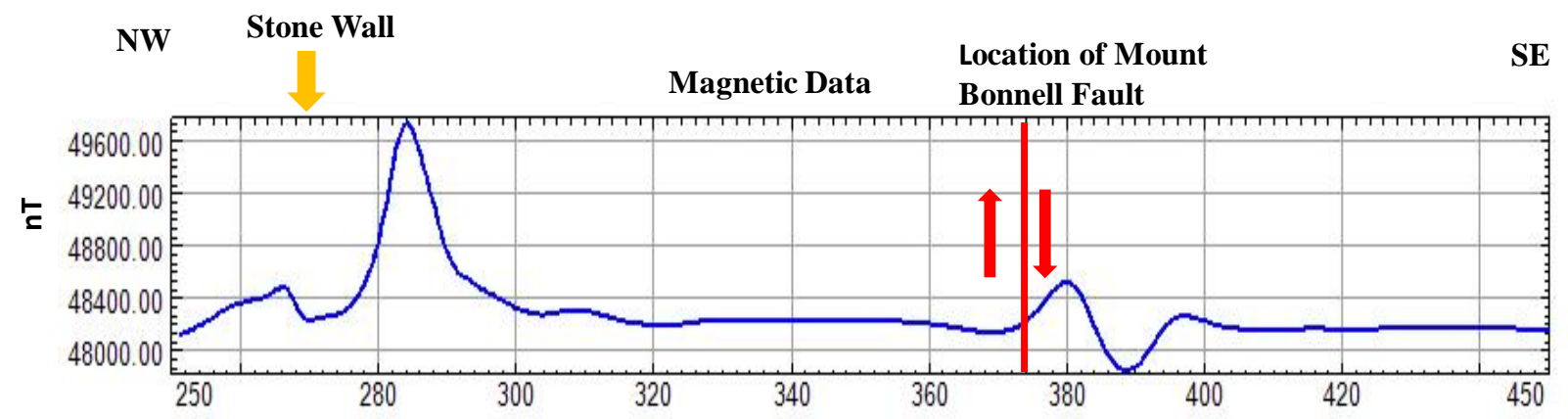

Conductivity Data

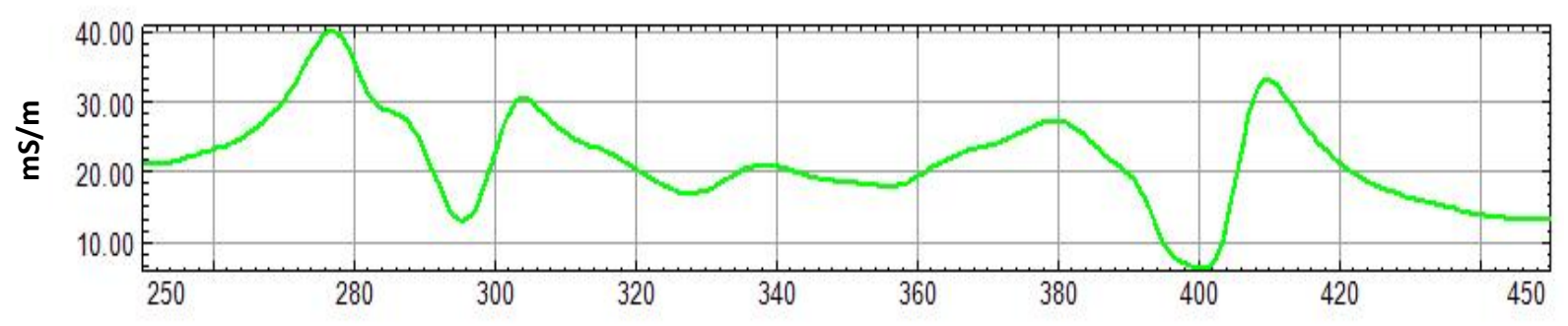

Figure 4: Magnetic and conductivity data across the Mount Bonnell fault. A magnetic high, conductivity high and low anomalies are observed between the stations 270 and 300 feet. Another anomaly on both profiles, caused by a buried pipe, is shown between the stations at 370 and 410 feet. The location of Mount Bonnell is referenced based on the geological data (Hauwert, 2009).

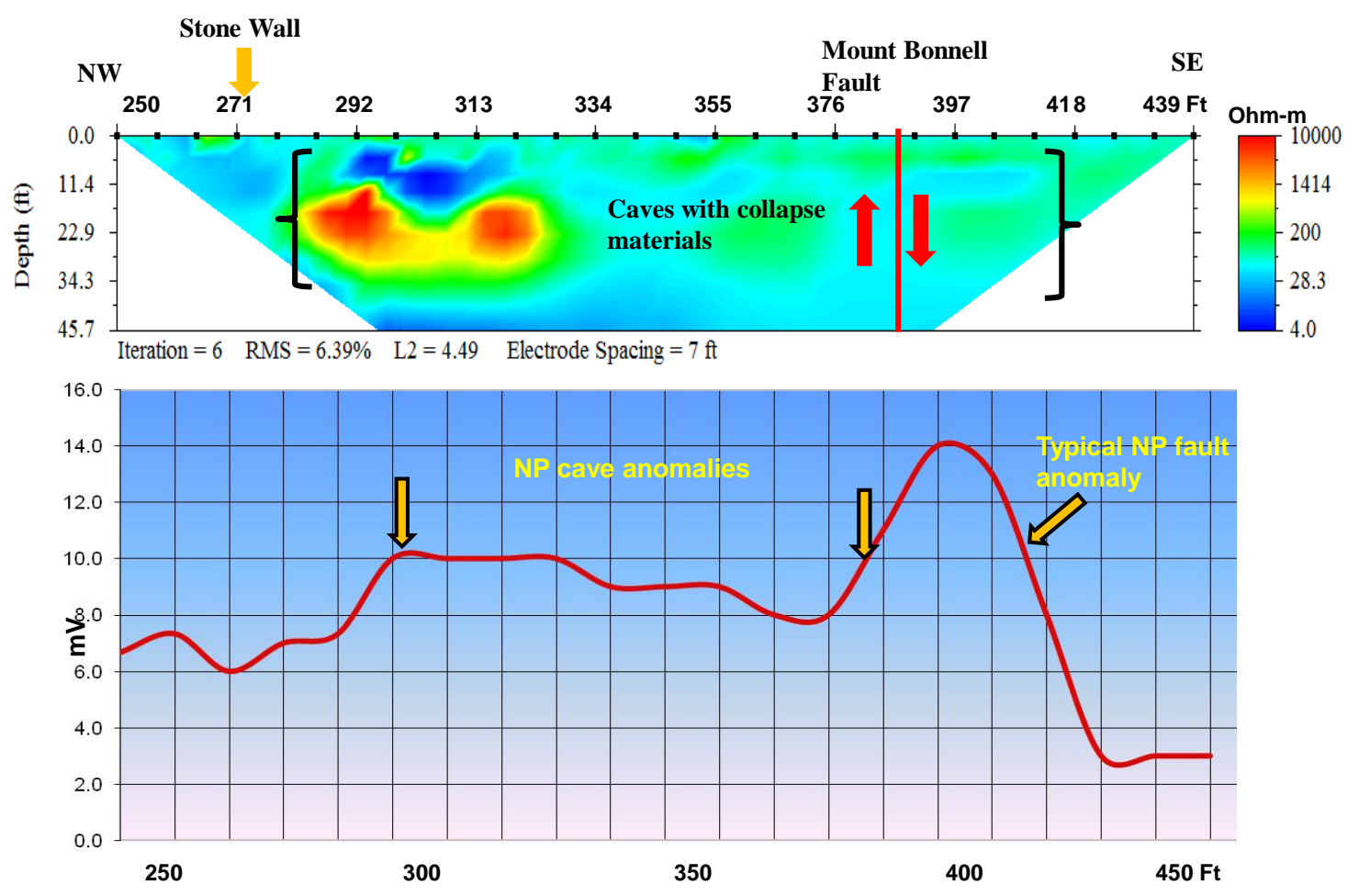

Figure 5. Resistivity imaging (above) and NP (below) data across the Mount Bonnell fault. Note the correlation between the two data sets except that the resistivity data does not indicate the fault. 

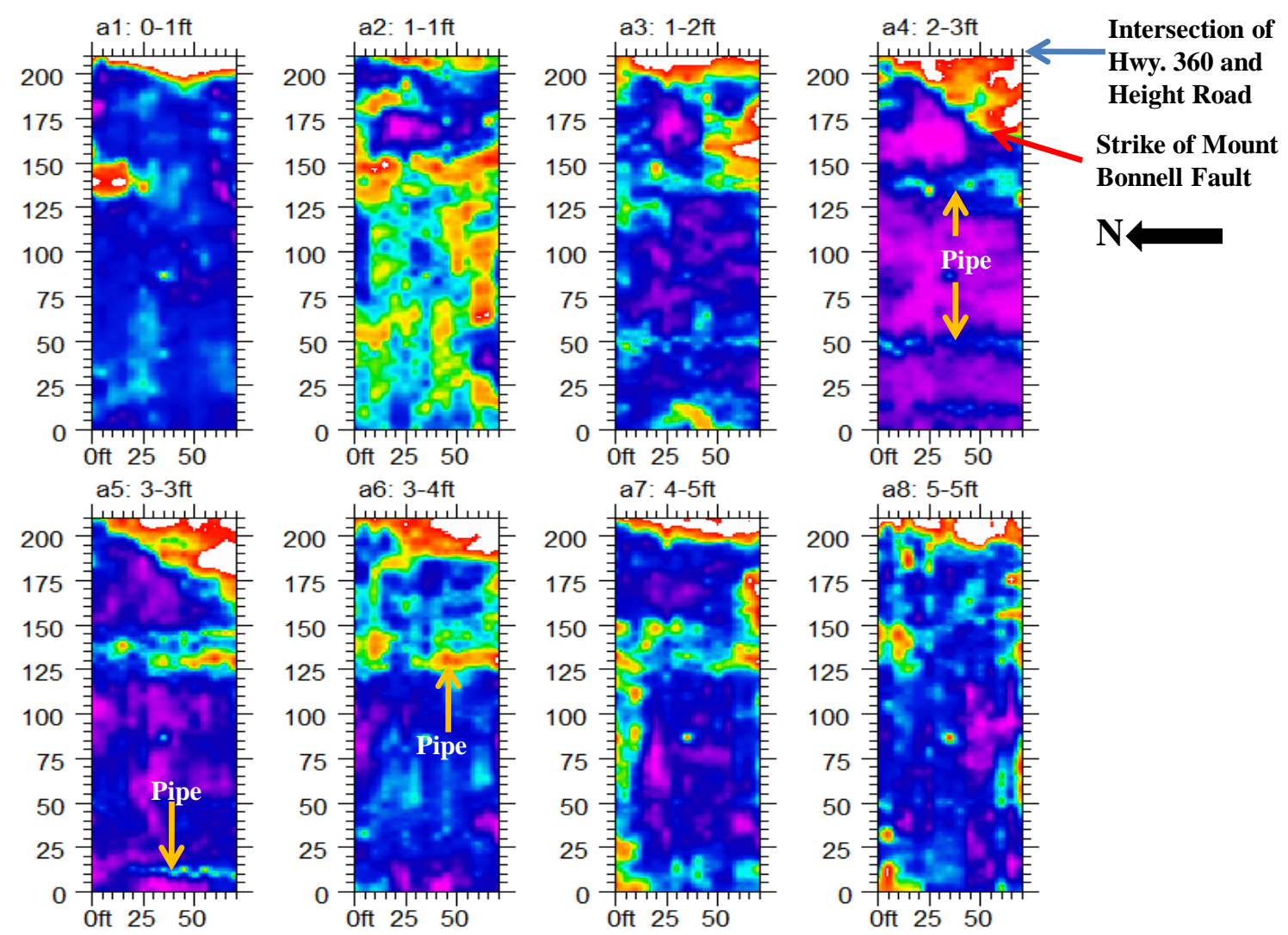

Figure 6: 3-D GPR depth slices showing the strike of Mount Bonnell fault and subsurface pipes.

Table 1: Karstic features located by geophysical surveys at Height Drive.

\begin{tabular}{|l|c|c|c|c|c|}
\hline \multirow{2}{*}{$\begin{array}{l}\text { Geophysical } \\
\text { Methods }\end{array}$} & \multicolumn{5}{|c|}{ Karstic Features } \\
\cline { 2 - 6 } & Cave & Sinkhole & $\begin{array}{l}\text { Collapse } \\
\text { Materials }\end{array}$ & $\begin{array}{l}\text { Faults and } \\
\text { Fractures }\end{array}$ & Conduit \\
\hline Magnetic & $\checkmark$ & & & & \\
\hline Conductivity & $\checkmark$ & & $\checkmark$ & $\checkmark$ & \\
\hline Resistivity & $\checkmark$ & $\checkmark$ & & $\checkmark$ & $\checkmark$ \\
\hline NP & $\checkmark$ & & $\checkmark$ & $\checkmark$ & $\checkmark$ \\
\hline GPR & $\checkmark$ & $\checkmark$ & $\checkmark$ & & $\checkmark$ \\
\hline TOTAL & $\checkmark$ & $\checkmark$ & & & $\checkmark$ \\
\hline
\end{tabular}

\section{West Park Drive at Highway 360}

The site map of the study area is given in Figure 7. The geophysical fieldwork took two stages: I performed reconnaissance magnetic, conductivity and GPR surveys along the orange line; second, I focused on the observed anomalies from the above-mentioned methods, and collected additional resistivity and NP surveys. Thus, the locations of the surveys are based on the site conditions with respect to geophysical methods. 
The magnetic and conductivity data are shown in Figure 8. The magnetic values vary between 48,200 and 47,200 nT between the start and end of the profile. The magnetic data indicate two significant changes between the stations at 400 and 520 feet and the stations at 700 and 800 feet, respectively (see Figure 8). The approximate location of the MBF (Hauwert, 2009) is shown on the magnetic data in Figure 8. The conductivity values also show anomalies at these locations. A first vertical derivative of the magnetic data indicates shallow anomalies, which may be caused by cultural features or shallow small-scale faults associated with the MBF (Figure 9). The power-spectrum of the magnetic data indicates that the deepest magnetic sources are within the range of 60 to 80 feet deep. Figure 10 shows the resistivity imaging and NP data. Note that the resistivity data was taken between the stations at 250 and 547 feet whereas the NP data is collected between stations at 0 (zero) and 740 feet. The reason for this was that the resistivity profile was limited by driveways. Both data sets show locations of significant karstic features and faults. In addition, the resistivity data show a fault anomaly at the station 420 feet. A section of the GPR data showing a significant collapsed feature is given in Figure 11. The GPR data also shows a shallow fault at about 425 feet, which correlates well with the resistivity data. The GPR data do not indicate any anomaly over a significant resistivity anomaly, which was observed at station 490 feet at a depth of 18 feet and below. This is probably due to the depth exploration of the GPR data, which is about 7 feet. There are other GPR anomalies (small sinkholes, small caves and collapsed areas) along the profile; but I will examine these in another paper or presentation.

In summary, the magnetic data showed several shallow faults and/or fracture zones, which correlate well with the resistivity and NP data. The resistivity data show two faults, which are located about 250 feet to the northwest of the MBF projected by the geological data (Hauwert, 2009). The conductivity data shows high anomalies the between stations at 200 and 450 feet, which is probably due to the shallow faults and fracture zones. The GPR data indicate a significant collapsed area, northwest side of which is controlled by a shallow fault. The location of this fault correlates well with the resistivity data. The NP data show fault and karstic anomalies along the entire length of the profile. There is also a significant gradient along the NP profile towards the southeast. This gradient is probably caused by the ground water movement within the conduits of the Edwards Aquifer. At the site, there is repaired, patched asphalt where the faults are located by the geophysical data. Findings of geophysical surveys are given in Table 2. 


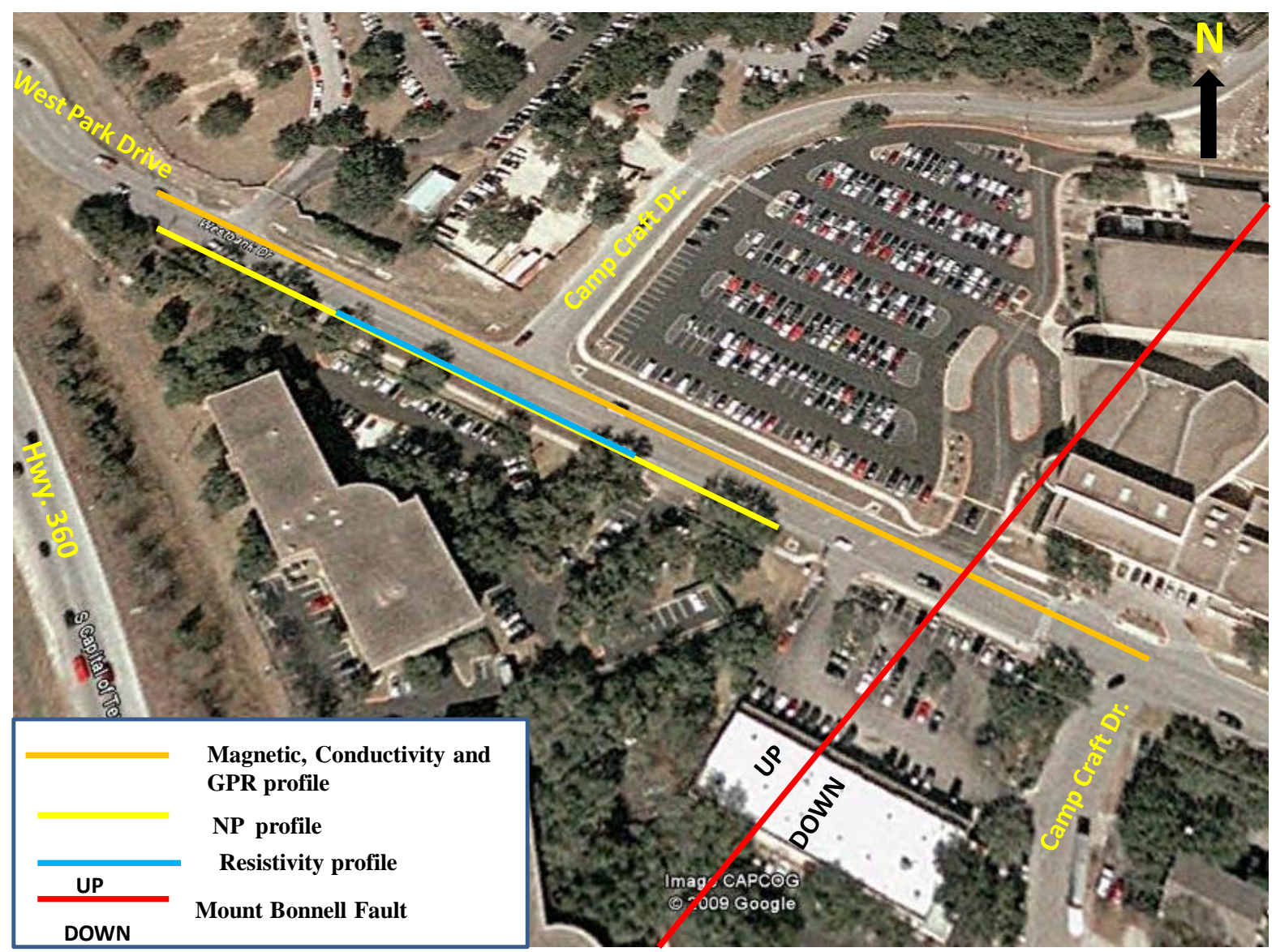

Figure 7: Site map showing the location of geophysical profiles and the MBF based on the geological data (Hauwert, 2009). 

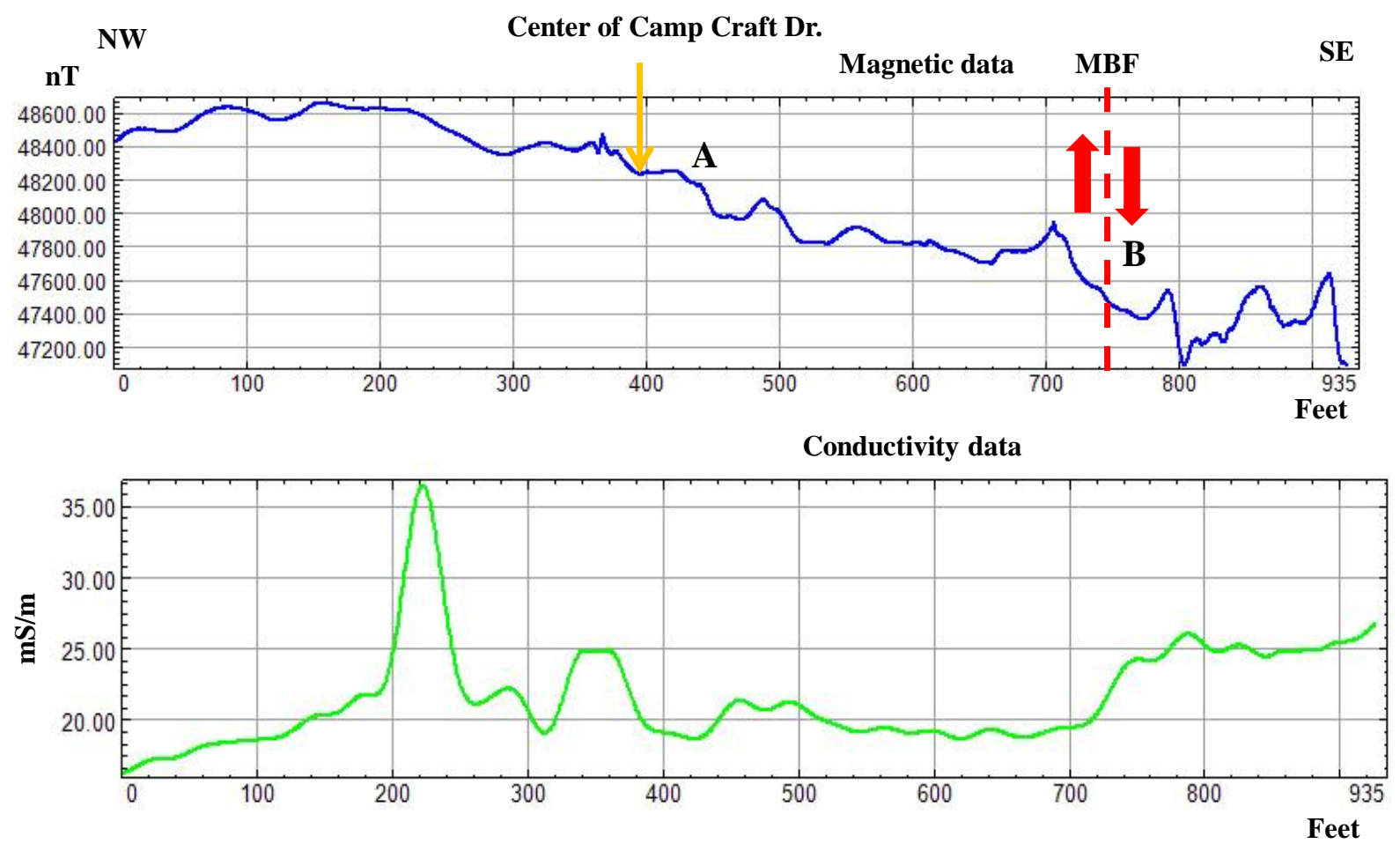

Figure 8: Magnetic and conductivity data across the MBF. Location of the MBF is referenced based on the geological data (Hauwert, N., 2009). Note the two locations (A and B) on the magnetic profile where the slopes of the magnetic data change significantly, which correlates with the conductivity data.

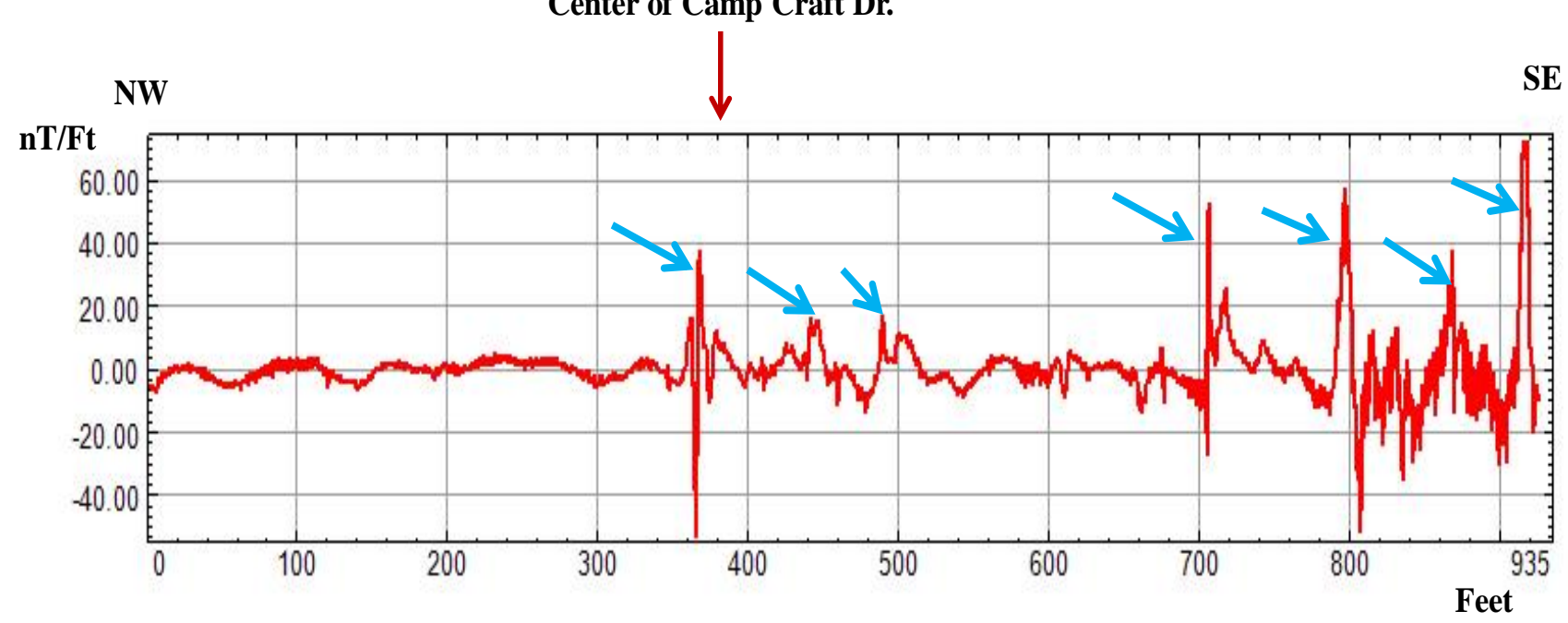

Figure 9: The first vertical derivative of the magnetic anomaly indicates high-gradient zones (locations shown with blue arrows) which may be related to shallow cultural features or small-scale faults/fractures associated with the MBF. 


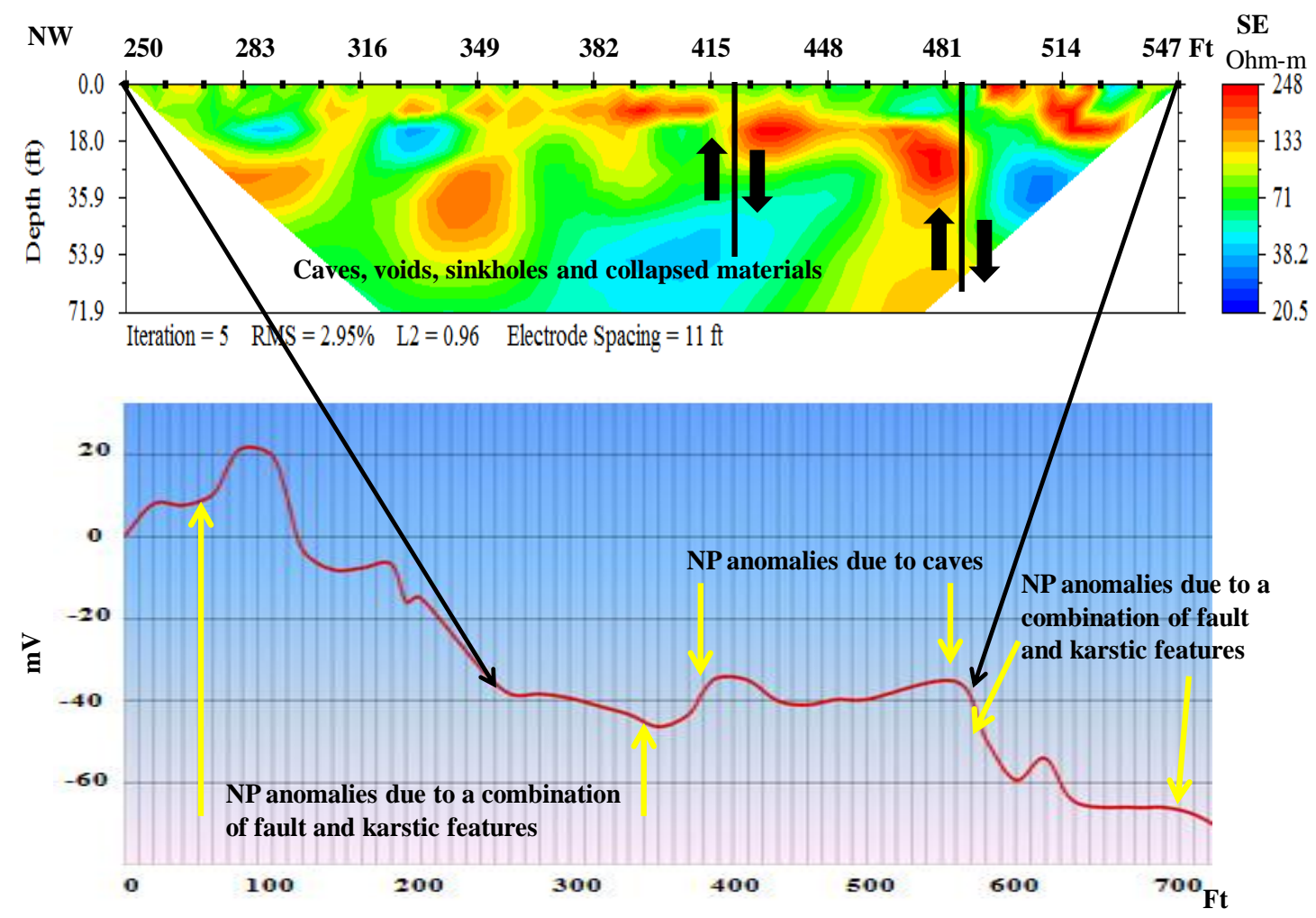

Figure 10: Resistivity imaging (above) and NP (below) data across the MBF at West Park Drive. Horizontal scales of both data sets are the same. Note the steep NP gradient towards the southeast.

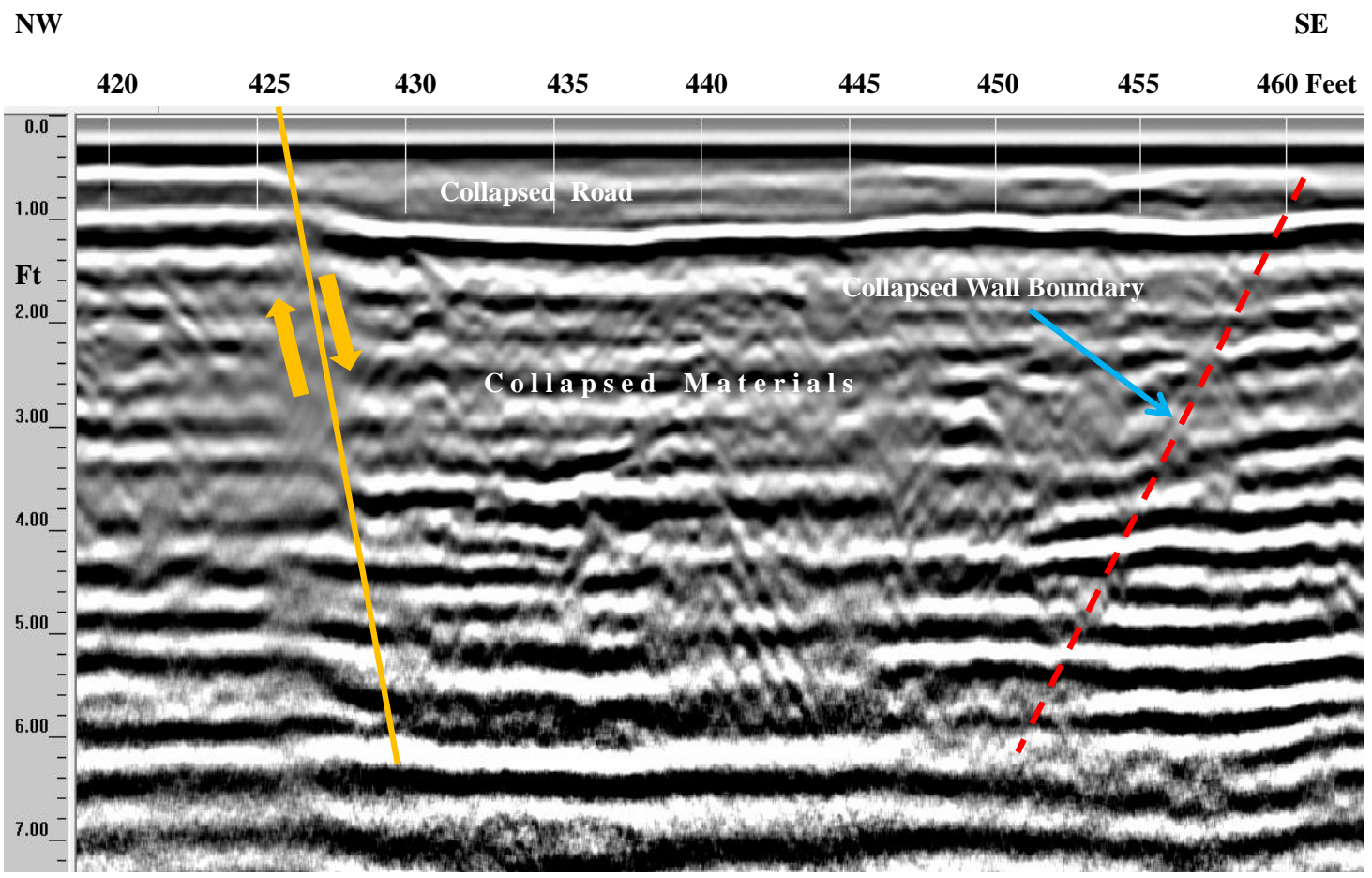

Figure 11: Section of GPR data (400 MHz) across the MBF at West Park Drive. The data indicate a shallow fault and associated collapsed subsurface materials. The width of the collapsed area is about 40 feet. 
Table 2: Karstic features located by geophysical surveys at West Park Drive.

\begin{tabular}{|l|c|c|c|c|c|}
\hline \multirow{2}{*}{$\begin{array}{l}\text { Geophysical } \\
\text { Methods }\end{array}$} & \multicolumn{5}{|c|}{ Karstic Features } \\
\cline { 2 - 6 } & Cave & Sinkhole & $\begin{array}{l}\text { Collapse } \\
\text { Materials }\end{array}$ & $\begin{array}{l}\text { Faults and } \\
\text { Fractures }\end{array}$ & Conduit \\
\hline Magnetic & & & & $\checkmark$ & \\
\hline Conductivity & & & $\checkmark$ & $\checkmark$ & \\
\hline Resistivity & $\checkmark$ & & & $\checkmark$ & $\checkmark$ \\
\hline NP & $\checkmark$ & & $\checkmark$ & $\checkmark$ & \\
\hline GPR & $\checkmark$ & & $\checkmark$ & $\checkmark$ & $\checkmark$ \\
\hline TOTAL & $\checkmark$ & & & $\checkmark$ & $\checkmark$ \\
\hline
\end{tabular}

\section{Bee Cave Road Site at Camp Craft Road}

A site map of the study area including the locations of geophysical profiles and the MBF are shown in Figure 12. The geophysical surveys, except the GPR, were all conducted along the grassy area between the two driveways of the West Lake Bible Church and West Lake Animal Hospital. The GPR data was collected along Bee Cave Road adjacent to other profiles (see Figure 12). There is an incipient sinkhole (recharge area) in the study area.

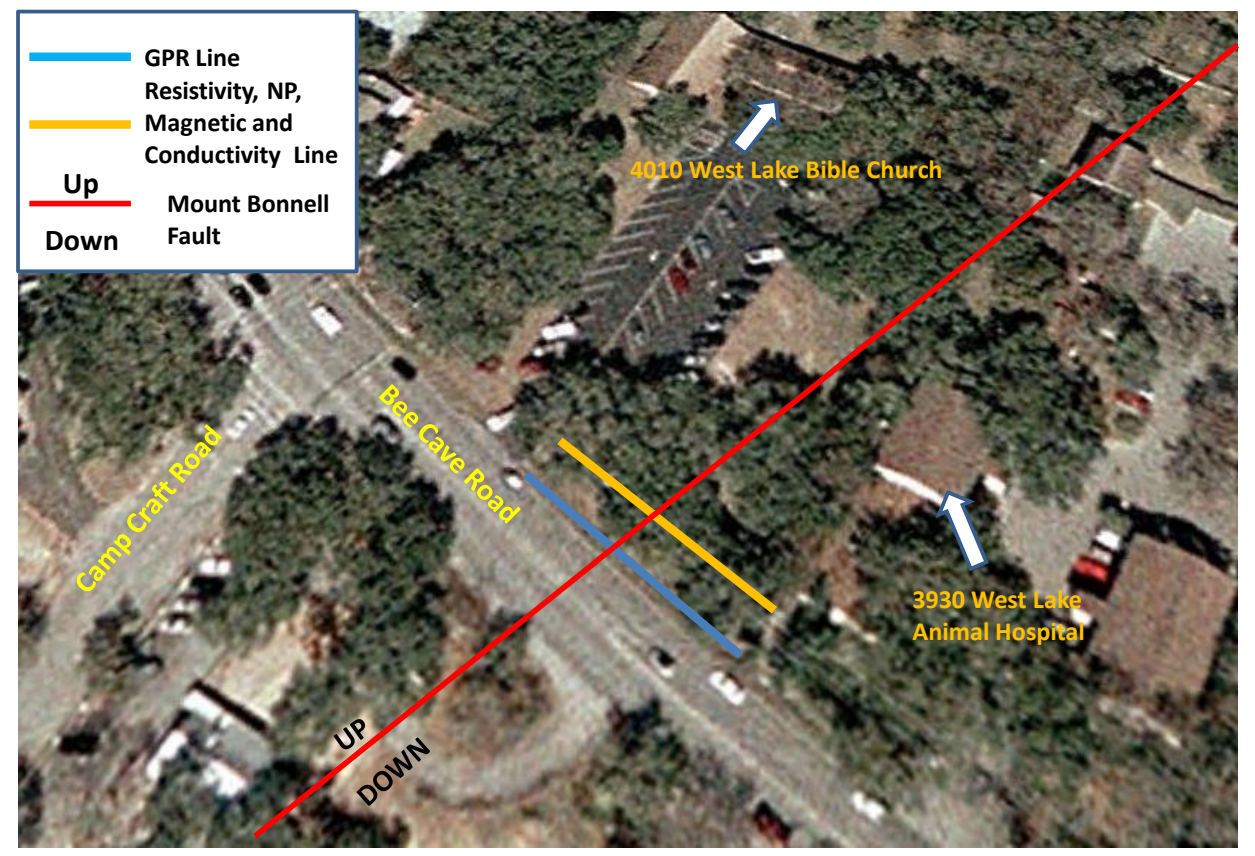

Figure 12: Site map showing locations of geophysical profiles and the MBF.

The magnetic and conductivity data are given in Figure 13 show high magnetic and conductivity anomalies between the stations 279 and 330 feet. The source of these anomalies appears to be subsurface. The incipient sinkhole is located at the station at 265 feet. The resistivity and NP data are given in Figure 14. The resistivity data show karstic anomalies (cave, sinkhole, collapsed materials, etc.) along entire length. The high magnetic and conductivity anomalies correlate well with the locations low 
resistivity material $(\leq 20$ Ohm-m). Based on this correlation, the source of the magnetic and conductivity anomalies can be attributed to magnetic soils in the subsurface. The NP data shows a very unique "U" type anomaly along the profile. The NP values range between 10 and $-38 \mathrm{mV}$. The NP anomaly appears to be caused by a conduit flow in the subsurface. Two sections of GPR are given in Figures 15 and 16. Both data sets indicate a sinkhole and a collapsed area, respectively. A change in elevation from high to low towards the southeast is observed on Bee Cave Road where the collapsed area starts.

In summary, the magnetic and conductivity data show high amplitude anomalies which correlate well with the low resistivity materials between the surface and 25 feet below. The NP data display a simple but strong amplitude anomaly between the stations at 215 and 350 feet, indicating a conduit flow in the subsurface. The GPR data show a sinkhole and a collapsed area along the profile taken on the road. None of the geophysical methods appears to detect the MBF's signature. This may be due to the dominating

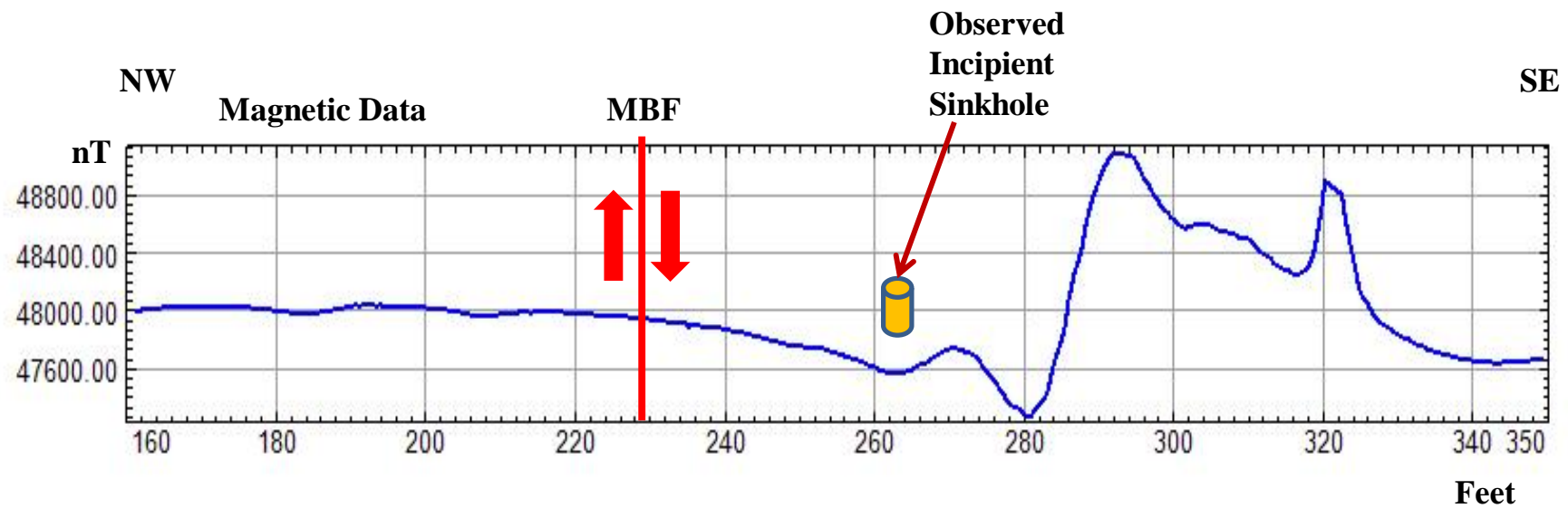

$\mathrm{mS} / \mathrm{m} \quad$ Conductivity Data

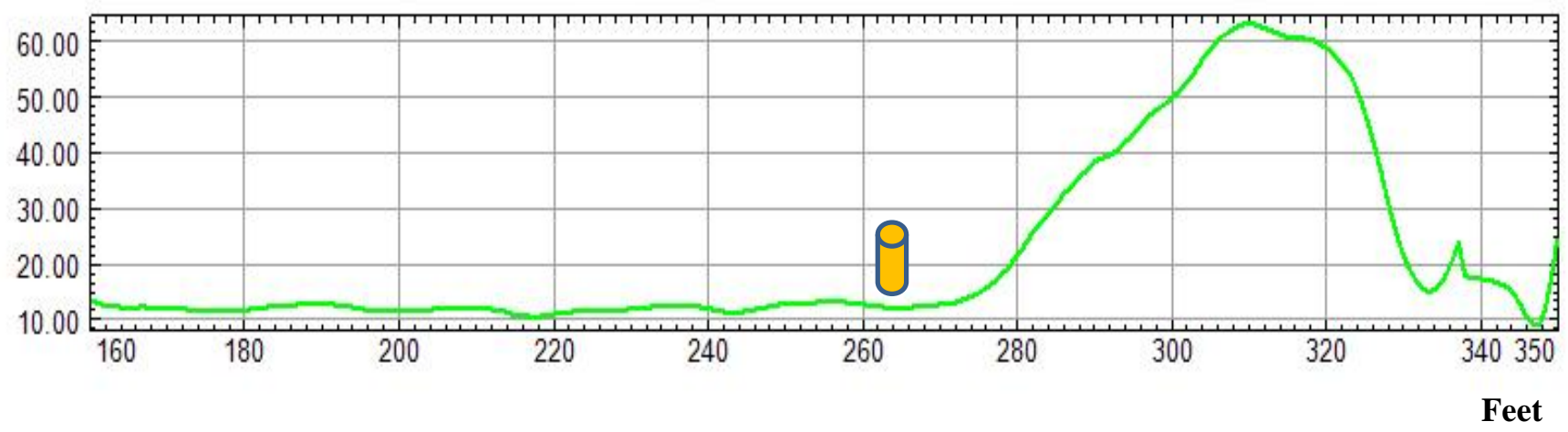

Figure 13: Magnetic and conductivity profile across the MBF. There is a ferrous electrical pole near the station at 250 fee, but observed high magnetic and conductivity anomalies between the stations at 260 and 330 appear to be caused by subsurface sources. 

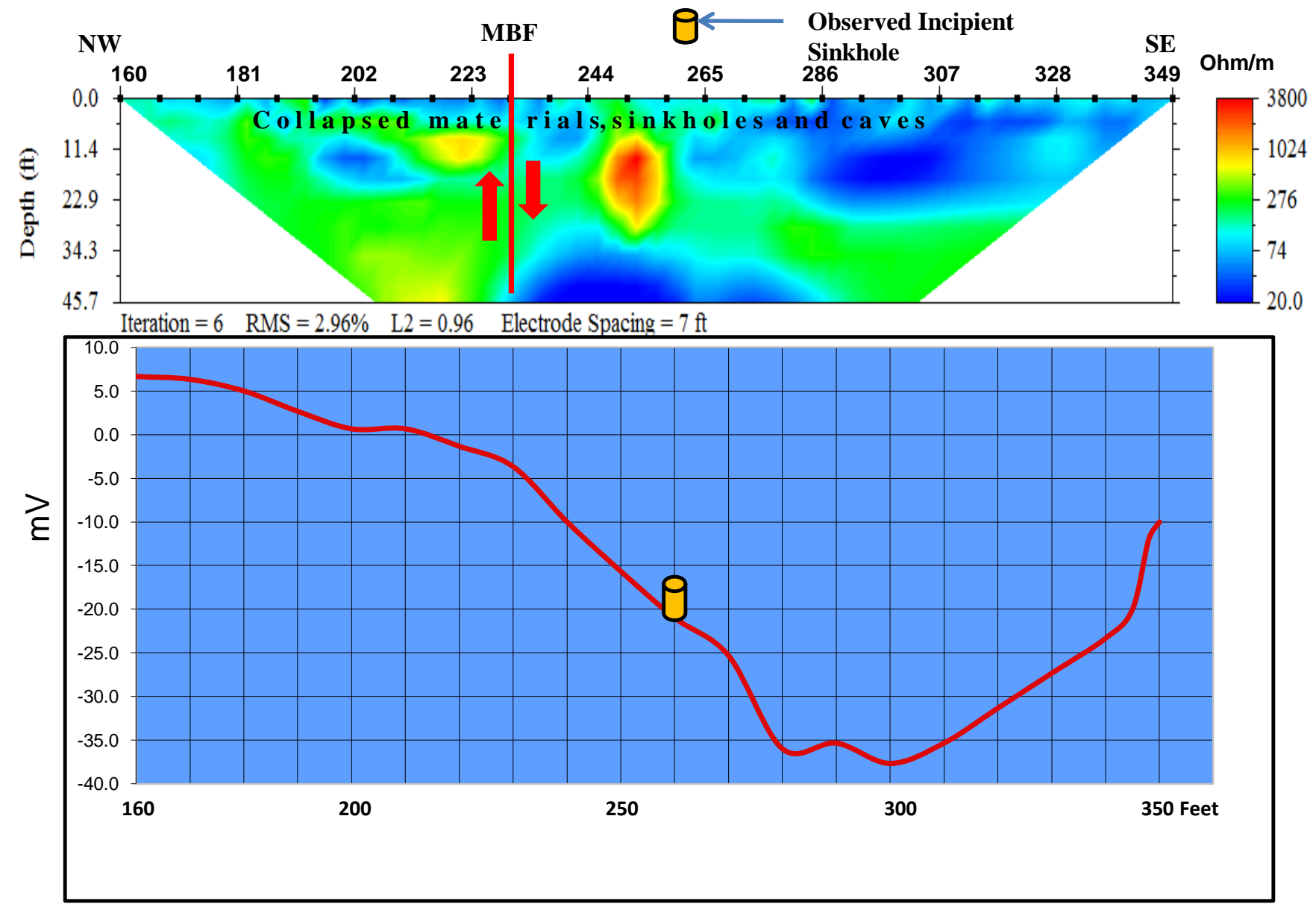

Figure 14. Resistivity (above) and NP (below) data across the MBF. Location of the MBF is given by Hauwert, Nico., 2009. 


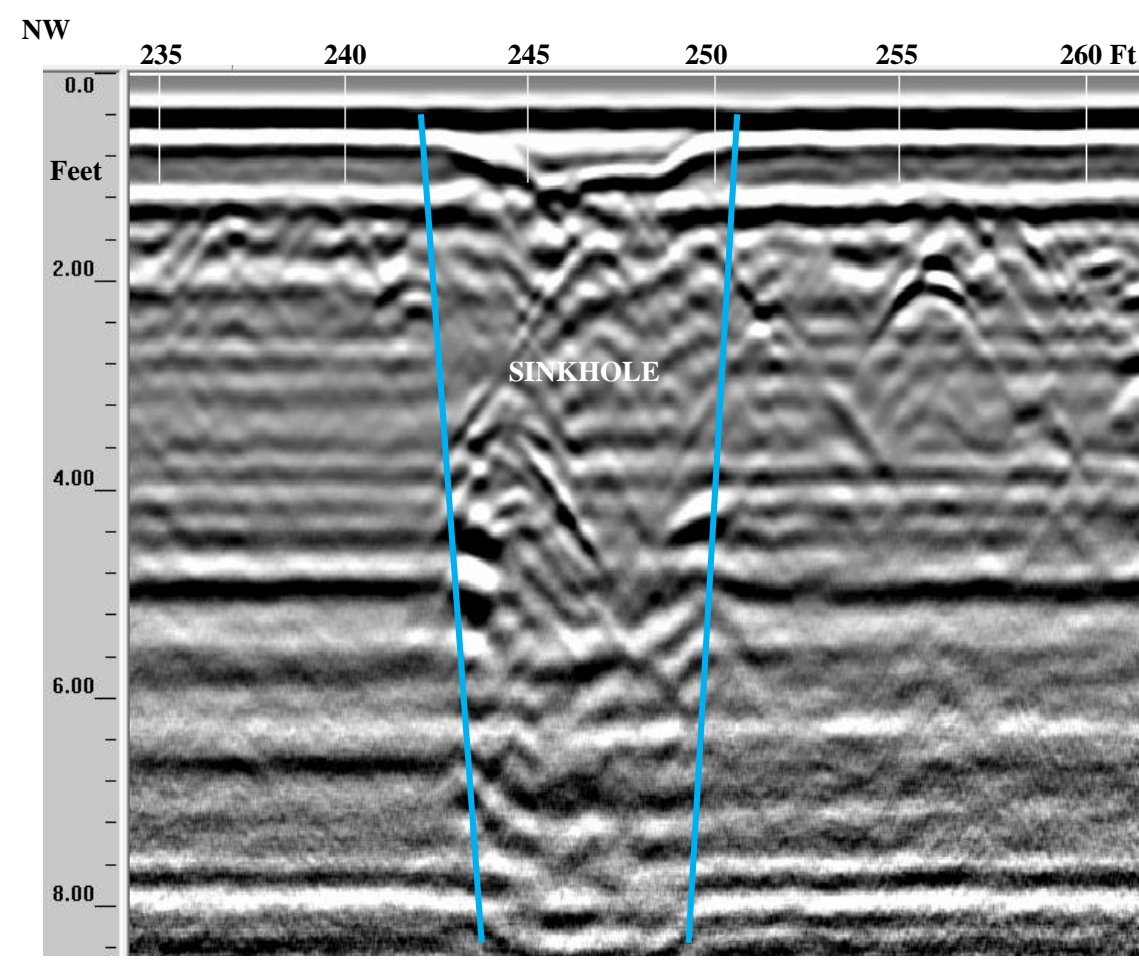

Figure 15. A section of GPR data across the MBF. A sinkhole is located between stations 242 and 252 feet. Note that the sinkhole is very close to the surface at the Bee Cave Road. Location of this sinkhole correlates well with the incipient sinkhole and the "sphere-like" high resistivity anomaly that are observed on the surface and the resistivity data, respectively.

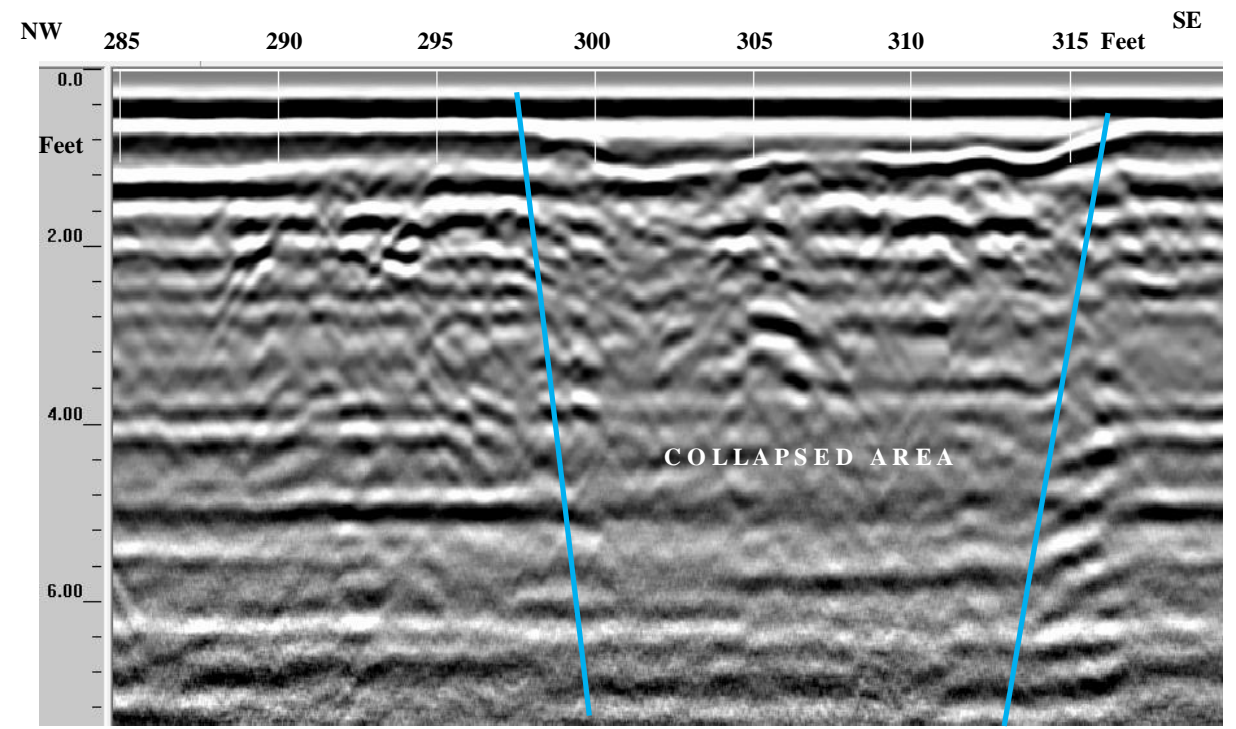

Figure 16. A section of GPR data across the MBF. A collapsed area, limited by the blue lines, is observed between stations 298 and 317 feet., which correlates well with the low resistivity anomalies (see Figure 14). 
Table 3: Karstic features located by geophysical surveys at Bee Cave Road.

\begin{tabular}{|l|c|c|c|c|c|}
\hline \multirow{2}{*}{$\begin{array}{l}\text { Geophysical } \\
\text { Methods }\end{array}$} & \multicolumn{5}{|c|}{ Karstic Features } \\
\cline { 2 - 6 } & Cave & Sinkhole & $\begin{array}{l}\text { Collapse } \\
\text { Materials }\end{array}$ & $\begin{array}{l}\text { Faults and } \\
\text { Fractures }\end{array}$ & Conduit \\
\hline Magnetic & $\checkmark$ & & & & \\
\hline Conductivity & $\checkmark$ & & $\checkmark$ & $\checkmark$ & \\
\hline Resistivity & $\checkmark$ & $\checkmark$ & & & $\checkmark$ \\
\hline NP & $\checkmark$ & & $\checkmark$ & $\checkmark$ & \\
\hline GPR & $\checkmark$ & $\checkmark$ & $\checkmark$ & $\checkmark$ & $\checkmark$ \\
\hline TOTAL & $\checkmark$ & $\checkmark$ & & & \\
\hline
\end{tabular}

\section{Discussion of Results/Conclusions}

All geophysical data obtained from the three sites across the MBF indicate significant subsurface anomalies. These anomalies appear to be due to caves, voids, collapsed materials, sinkholes, underground pipes, shallow faults and fracture zones. It should be noted that the magnitude of the NP anomalies are much stronger at the West Park Drive and Bee Cave Road than the Height Drive site. This observation may be related to the amount of the conduit flow within the Edwards Aquifer.

The GPR data taken along the roads indicate significant near-surface anomalies caused by collapsing soil, sinkholes and caves. It appears that these locations appear to be fixed periodically because of patched, repaired asphalt conditions observed on the roads.

In conclusion, data acquired and used to evaluate the effectiveness of geophysical methods in detecting karstic features and faults/fractures in the Austin area allowed correlation of unique and consistent anomalies with a known fault. It is clear from this study that integrated geophysical methods can be used to map Balcones faults and their associated karstic features quickly and inexpensively. Results of this study show the benefit of including as many as geophysical methods (five in this study) to both improve fault and karstic characterization of near-surface geology.

\section{References}

Collins, E.W., and Woodruff, C.M., 2001, Faults in the Austin, Texas, Area-Defining aspects of local structural grain, Austin Geological Society Guide Book 21, p.15-26.

Connor, C.B., and Sandberg, S.K., 2001, Application of Integrated Geophysical Techniques to Characterize the Edwards Aquifer, Texas, STGS Bulletin, March issue, p. 11-25.

Garner, L.E., Young, K.P., Rodda, P.U., Dawe, G.L., Rogers, M.A., 1976, Geologic map of the Austin area, Texas, in Garner, L.E., and Young, K.P., 1976, Environmental geology of the Austin area: an aid to urban planning: The University of Texas at Austin, Bureau of Economic Geology, scale 1:65,500.

Fitterman, D.V., and Stewart, M.T., 1986, Transient electromagnetic sounding for groundwater, Geophysics, v. 51, p. 995-1005.

Hauwert, N.M,. 2009, Groundwater flow and recharge within the Barton Springs Segments of the Edwards Aquifer, Southern Travis and Hay Counties, Doctor of Philosophy, The University of Texas at Austin. 
Rodda, P.U., Garner, L.E., and Dawe, G.L., 1970, Austin West, Travis County, Texas: The University of Texas at Austin Bureau of Economic Geology, Geologic Quadrangle Map 38, p.11.

\section{Acknowledgements}

I thank Dr. Nico Hauwert for showing the Mount Bonnell fault in the field and for numerous discussions, and a number of friends and colleagues who helped in the data acquisition. I thank Vsevolod Egorov for his contribution on the interpretation of the magnetic data. And last but not least, I am thankful to Esin Saribudak for her contribution to the graphical improvement and edition of the paper. This research project was funded by Environmental Geophysics Associates. 